\title{
Short Communication: Positional behavior of captive Bornean Orangutan (Pongo pygmaeus) at Bukit Merah Orangutan Island, Perak, Malaysia
}

\author{
SITI NORSYUHADA KAMALUDDIN ${ }^{1}$, SABAPATHY DHARMALINGAM ${ }^{2}$, BADRUL MUNIR MD-ZAIN,2, \\ ${ }^{1}$ School of Environmental and Natural Resource Sciences, Faculty of Science and Technology, Universiti Kebangsaan Malaysia. 43600, Bangi, Selangor, \\ Malaysia. Tel.: +60-389-213200, `email: abgbadd@ukm.edu.my, abgbadd1966@yahoo.com \\ ${ }^{2}$ Bukit Merah Orang Utan Island Foundation. Bukit Merah, Perak, Malaysia
}

Manuscript received: 6 December 2018. Revision accepted: 23 January 2019.

\begin{abstract}
Kamaluddin SN, Dharmalingam S, Md-Zain BM. 2019. Short Communication: Positional behavior of captive Bornean Orangutan (Pongo pygmaeus) at Bukit Merah Orangutan Island, Perak, Malaysia. Biodiversitas 20: 425-429. Bukit Merah Orangutan Island (BMOUI) is the only semi-captive orangutan conservation center in the Malay Peninsula. BMOUI promotes orangutan conservation through ex-situ efforts comprising rehabilitation, education, awareness, ecotourism, and research studies. This research aimed to determine the qualitative behavior aspects, especially focusing on the orangutan positional behavior on BMOUI. A focal instantaneous sampling method was carried out for 252 hours from December 2015 to November 2016. The qualitative results showed that the positional behaviors of a Bornean orangutan at BMOUI were divided into nine main categories, as follows: sitting, lying, clinging, forelimb-hindlimb suspension, standing, walking, running, brachiation, and multipositional modes. The most favorable position shown by a captive Bornean orangutan on BMOUI were dominated by sitting and lying postures. The variety of positional modes displayed in a semi-captive condition still maintained Bornean orangutan as the great ape originating from the tropical inhabitants of wooded environments.
\end{abstract}

Keywords: Bornean orangutan, Pongo pygmaeus, positional behavior

\section{INTRODUCTION}

The orangutan (Pongo pygmaeus) is the only available great ape in Asia in the family Pongidae (Roos et al. 2014). This arboreal and terrestrial primate species mostly inhabit tropical rainforest with restricted distribution on the islands of Sumatra and Borneo (Zhang et al. 2001; Ampeng et al. 2016). To date, three orangutan species have been recorded, namely Bornean orangutan (Pongo pygmaeus; Warren et al. 2001; Kamaluddin et al. 2018a), Sumatran orangutan (Pongo abelii; Md-Zain et al. 2013), and Tapanuli orangutan (Pongo tapanuliensis; Nater et al. 2017). Meanwhile, Bornean orangutan is divided into three subspecies, as follows: Pongo pygmaeus pygmaeus, Pongo pygmaeus morio, and Pongo pygmaeus wurmbii (Warren et al. 2001).

Orangutan allocates time differently to various behaviors depending on the condition of the habitat (Kuncoro 2004). The behavior variation of the orangutan is complemented with distinct positional behavior (Thorpe and Crompton 2005). Primate positional behaviors have been described as having postural and locomotor modes (Thorpe and Crompton 2006). Primate species displayed various positional modes compared to the other mammals based on ecological and morphological features (Manduell et al. 2012). Those various positional and postural modes have been studied in many primate species, such as Gorilla gorilla gorilla (Remis 1995), Pan troglodytes (Doran 1996), Symphalangus syndactylus (Fleagle 1976;
Michilsens et al. 2010), Macaca fuscata (Koari 2002), Macaca fascicularis (Cant 1988; Md-Zain et al. 2010), Macaca nemestrina (Ruslin et al. 2010), Pygathrix nemaeus (Workman and Covert 2005), Trachypithecus delacouri (Workman and Schmitt 2012), and Trachypithecus obscurus (Ch'ng and Md-Zain 2009; MdZain and Ch'ng 2011; Ruslin et al. 2019).

Data on orangutan positional behavior in the natural habitat have been documented by several researchers (Isler 2003; Manduell et al. 2012; Putt 2009; Thorpe and Crompton 2006). Orangutan facilitates different postural modes for their terrestrial and arboreal lifestyle due to their special body structure (Delgado and van Schaik 2000). Orangutan has long forelimbs with hook-like hands, short hindlimbs with hand-like feet, and highly flexible hip and shoulder joints (Delgado and van Schaik 2000). In the wild, orangutan dominantly performs suspensory posture and movement (Putt 2009; Thorpe and Crompton 2005). To date, positional behavior has never been investigated for a captive orangutan in Malaysia except in several studies in Indonesia (Manduell et al. 2011; Manduell et al. 2012; Thorpe and Crompton 2006). In addition, most positional studies focus on the wild orangutan and emphasize a few activities, such as resting, feeding, and moving (Descovich et al. 2011). Thus, this study aimed to identify and describe the positional modes of semi-captive orangutan on BMOUI to provide adequate knowledge of the variety of great ape behaviors in a captive environment. 


\section{MATERIALS AND METHODS}

\section{Study site}

Bukit Merah Orangutan Island (BMOUI), Perak (100 $40^{\prime} 33.9^{\prime \prime} \mathrm{E}, 05^{\circ} 00^{\prime} 32.1^{\prime \prime} \mathrm{N}$ ), is located on the Malay Peninsula (Figure 1; Kamaluddin et al. 2018b). Ecotourism is common in the study area in addition to being a captive orangutan conservation center. The island is estimated to be about $35 \mathrm{ha}$, and it is covered by secondary tropical forest. Five acres were provided to build four enclosures as the orangutan release center. All the enclosures are separated by electronic hot fire fences. Various structures like ropes, feeding devices, and wooden platforms have been set up in the outdoor enclosures, which consist of secondary forest. The orangutan has daily access to the outdoor enclosures from 9:00 am to 5:00 pm. Tourists can observe the orangutan moving freely by walking through the tunnel located in the middle of the enclosures (Md-Zain et al. 2013).

\section{Data collection}

The observation was carried out almost over 1 year, from December 2015 to November 2016, as part of behavioral research that also included quantitative data for the daily activity budget. However, in this paper, we only present qualitative data focusing on positional behavior (Md-Zain et al. 2014). The data were collected randomly for 15 individuals of orangutan with different age-sex classes using focal instantaneous sampling. Sampling was conducted from 9:30 am to 5:00 pm in 5-minute intervals for sessions lasting 1 hour (Kamarul et al. 2014; Hambali et al. 2016). Postural behaviors were measured using the standard protocol from Martin and Bateson (1986) and Morrogh Bernard et al. (2002). The description of the positional behavior of the orangutan was recorded following Ampeng and Md-Zain (2012), Ch'ng and MdZain (2009), and Hunt et al. (1996).

\section{RESULTS AND DISCUSSION}

The postural modes of the orangutan were divided into five main categories, namely sitting, lying, clinging, suspension, and standing. Meanwhile, the locomotor modes were divided into three main categories, which were walking, running, and brachiation. Multipositional modes were also recorded in this study, representing the combination of many postural and locomotion modes at one time.

\section{Postural modes \\ Sitting}

The sitting posture of the orangutan on BMOUI mostly appeared in three categories, which were sit in, sit out, sit in/out, and angled sit. Based on the observation, the dominant sitting posture for the orangutan was the sit-in position.

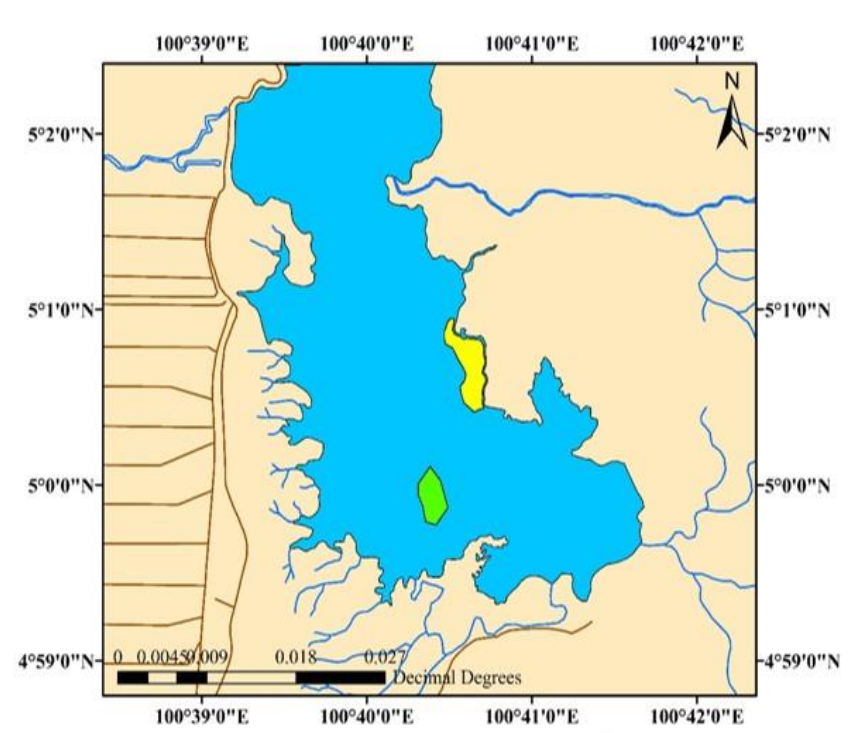

Legend

Bukit Merah Orang Utan Island (BMOUI)

BJ Island

Bukit Merah Lake

Main Land

Road

River

Figure 1. Study site of Bukit Merah Orang Utan Island, Malaysia

Sit in. This position often occurred terrestrially on BMOUI during the resting and feeding period. It is mainly supported by the ischia, which are close to the heels and usually touch the base of the thigh. The knee and hip are tightly bent with the hindlimbs. The body weight of the ischia is roughly held by the feet (Figure 2.A). To support the body weight, the ischia and feet support the stratum horizontally (Putt, 2009; Thorpe \& Crompton, 2005, 2006). In the resting period, the forelimbs were often bent on the knee, while the body curved to the front during feeding activity (Hunt et al. 1996).

Sit out. This position involves sitting with the hindlimbs or both feet out (Figure 2.B). The ischia support most of the body weight, while the feet are mostly used for balance (Rose 1977).

Sit in/out. One hindlimb is extended, while the other is flexed (Figure 2.C; Hunt et al. 1996; Thorpe and Crompton 2006).

Angled sit. This position is observed when the hindlimbs are close to the hip and the forelimbs grip the branch (Figure 2.D). The distribution of body weight differs from those on a horizontal substrate (Fleagle 1978). This position was rarely observed in adult orangutans on BMOUI. 


\section{Lying}

Lateral lie. This mode of position is usually exhibited during the inactive phase and involves the elbows supported by the upper part of the body (Figure 2.E). The substrate is touched by all lateral body segments (Hunt et al. 1996; Philips 2011; Sugardjito and Van Hoof 1986). This position was mostly observed terrestrially during hot weather on BMOUI. It rarely occurred on the tree branches.

Back lie. All body weight rests mostly on the dorsum part (Hunt et al. 1996). This posture was usually displayed by all the orangutans during the resting time (Figure 2.F).

\section{Clinging}

This posture is mostly exhibited in two types of modes, which are bimanual clinging and unimanual forelimb clinging (Hunt et al. 1996). A flexed limb posture is most frequent on vertical or subvertical supports (Hunt et al. 1996; Myatt et al. 2011; Putt 2009).

Bimanual clinging (= vertical clinging). Both Bukit Merah orangutan hands grip the substrate with the elbows bent (Figure 2.G). The torso is in orthograde or suborthograde position, while the forelimbs are toward the body. The hindlimbs are bent at the knee and hip. At least half of the body weight is supported by the hindlimbs (Manduell 2008). In all cases, the elbow, knee, and hip are bent (Richard 1985).

Unimanual forelimb clinging (= arm hang). One of the orangutan hands grips the substrate with unusual support from other parts of the body (Figure 2.H). In this posture, more than half the body weight is supported by the forelimbs to grip a substrate above the body (Fleagle 1976; Thorpe and Crompton 2006).

\section{Forelimb-hindlimb suspended (= arm-foot hang)}

This position involves suspension by a forelimb and a foot with a subhorizontal position (Cant 1987). The limbs are extended (Thorpe and Crompton 2006). This position is different from forelimb suspend, in which the torso position is more pronograde (Thorpe and Crompton 2006).

Ipsilateral forelimb-hindlimb. This position involves suspension of the body using torso pronograde with a forelimb and hindlimb on the same side of the body (Figure 3.A)

Contralateral forelimb-hindlimb. This comprises a suspension of the body using torso pronograde with a forelimb on one side and hindlimb on the other side of the body (Figure 3.B)

\section{Standing}

Quadrupedal stand. This position involves four limbs standing horizontally or subhorizontal on the substrate (Figure 3.C). The elbow and knee are enlarged, and the trunk is near horizontal (Putt 2009).

Extended bipedal stand. In this stance, the hip and knee are completely expanded and not supported by the forelimbs (Figure 3.D). The trunk is near orthograde, and this position is described as human-like standing (Myatt 2011; Thorpe et al. 2007).

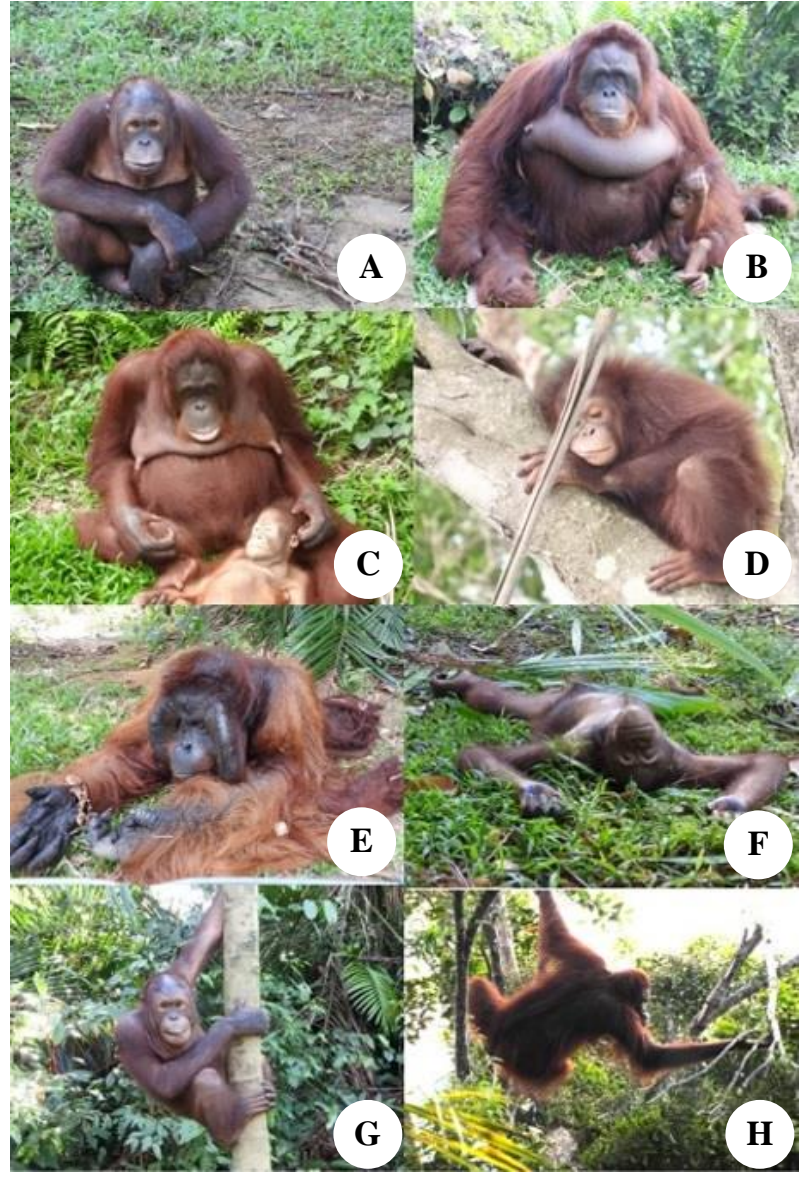

Figure 2. A. Sit-in posture, B. Sit-out posture, C. Sit-in out posture, D. Angled posture, E. Lateral lie posture, F. Back lie posture,G. Bimanual clinging posture, $\mathrm{H}$. Unimanual forelimb clinging posture

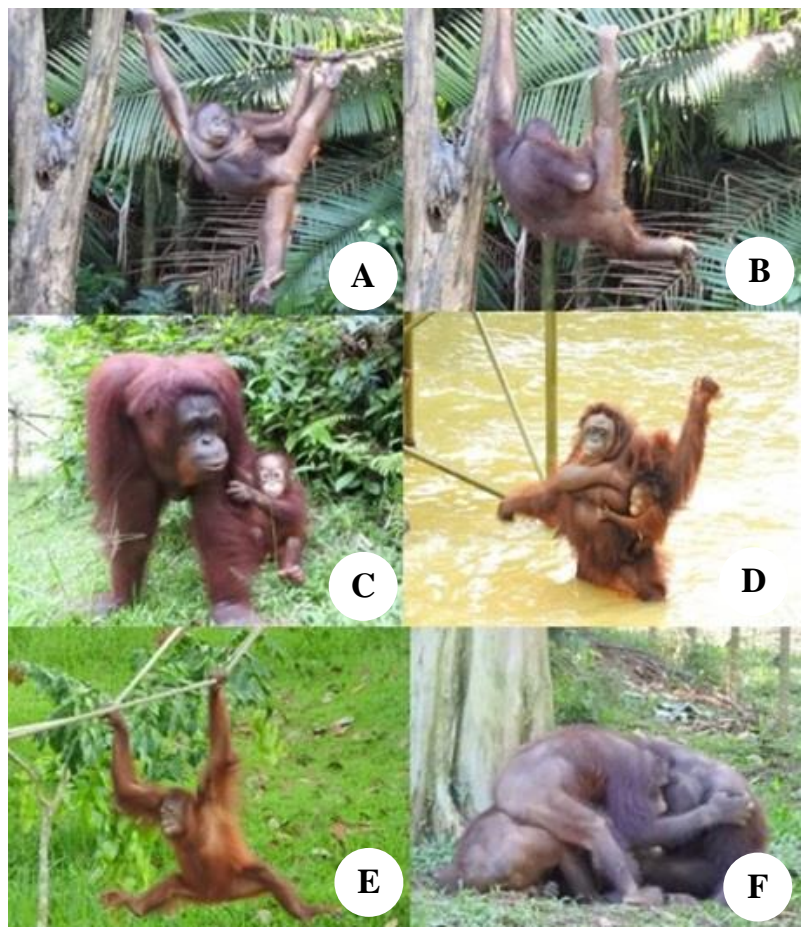

Figure 3. A. Contralateral forelimb-hindlimb suspend posture,B. Ipsilateral forelimb-hindlimb suspend posture, C. Quadrupedal stand, walk and run posture, D. Bipedal stand, walk and run posture, E. Brachiation posture, F. Multi-positional modes 


\section{Locomotor modes Walking}

Symmetrical gait walking (quadrupedal walking). Symmetrical gaits mostly occur in primate walking (Cant 1987; Manduell 2008). Walking is usually a diagonal sequence with extended limbs (Manduell et al. 2011; Myatt and Thorpe 2011). This mode of locomotion supports significant stability (Figure 3.C) of the Bukit Merah orangutan body weight compared with bipedal movement (Gebo-Daniel 1996).

Extended bipedal walking. In this walking, there is support by the hindlimbs via an extended hip and knee (Cant 1987; Putt 2009). This mode of locomotion is comparable to human walking (Figure 3.D; Hunt et al. 1996; Myatt and Thorpe 2011). In the wild, all great apes can perform bipedal walking, and it mostly occurs in the arboreal context (Thorpe and Crompton 2006).

\section{Running}

This mode of locomotion is usually observed when the Bukit Merah orangutan is in playing activity or showing fear toward something.

Quadrupedal running. This type of running uses asymmetrical or irregular gaits for fast locomotion (Figure 3.C; Hunt et al. 1996).

Bipedal running. This involves a similar posture to bipedal walking, but with fast movement (Figure 3.D). The most running activity of primates is actually fast walking (Hunt et al. 1996).

\section{Brachiation}

This involves orthograde suspensory locomotion by hand-over-hand motion to grip the substrate (Figure 3E; Gebo-Daniel 1996). Half the body weight is supported by the forelimbs, and only some are supported by the hindlimbs (Myatt 2011; Manduell et al. 2012).

\section{Multipositional modes}

This positional behavior combines all the modes of posture and movement at one time (Figure 3.F). These modes have usually been observed among sub-adults during playing activity. They include terrestrial and arboreal postures and locomotion, but they are mainly observed on the ground.

In conclusion, Nine types of positional behaviors were exhibited by the Bukit Merah orangutan, namely sitting, lying, clinging, suspend, standing, walking, running, brachiation, and multipositional modes. Sitting comprised many categories, specifically sit in, sit out, sit in/out, and angled sit. Three types of lying positions were identified, namely lateral lying, back lying, and sprawling. The clinging posture was divided into bimanual clinging and unimanual forelimb clinging, while the suspend posture was separated into ipsilateral forelimb-hindlimb and contralateral forelimb-hindlimb. The standing positional modes involved quadrupedal and extended bipedal standing. Meanwhile, walking exhibited symmetrical gait and extended bipedal walking, while running was divided into quadrupedal and bipedal running. Brachiation displayed only a single type of posture, while the multipositional modes combined all the types of posture and movement. Positional behavior should be further studied by incorporating habitat utilization on BMOUI. Later, it will indirectly help the Bukit Merah Orangutan Island Foundation to formulate management plans for habitat enrichment and conservation in semi-captive conditions.

\section{ACKNOWLEDGEMENTS}

We thank Bukit Merah Orangutan Island (BMOUI) Foundation, especially Tan Sri Datuk Mustapha Kamal Abu Bakar and BMOUI staff for providing us with the necessary assistance during behavior observation. Research methods reported in this research adhered to the legal requirements of Malaysia and were approved by Department of Wildlife and National Parks under research permit (JPHL\&TN(IP):100-6/1/14 Jld 2(40). The authors acknowledge Universiti Kebangsaan Malaysia for providing the necessary funding, facilities, and assistance. This research was supported by Grants TD-2014-022, AP2015-004 and ST 2018-020 (Yayasan Emkay).

\section{REFERENCES}

Ampeng A, Md-Zain BM. 2012. Ranging patterns of critically endangered Colobine, Presbytis chrysomelas chrysomelas. Sci World J 2012: 594382. DOI: 10.1100/2012/594382.

Ampeng A, Shukor MN, Sahibin AR, Idris WMR, Ahmad S, Mohammad H, Madeline GP, Ali N, Bujang M, Hashim I, Bujang A, Md-Zain BM. 2016. Patterns of mineral lick use by Northwest Bornean orangutans (Pongo pygmaeus pygmaeus) in the Lanjak Entimau Wildlife Sanctuary, Sarawak, Malaysia. Eur J Wildl Res 62: 147-150.

Cant JGH. 1987. Positional behavior of female Bornean orang-utans (Pongo pygmaeus). Am J Primatol 12: 71-90.

Cant JG. 1988. Positional behavior of long-tailed macaques (Macaca fascicularis) in northern Sumatra. Amer J Phys Anthropol 76: 29-37.

Ch'ng C-E, Md-Zain BM. 2009. Locomotion and positional behaviour of dusky leaf monkeys (Trachypithecus obscurus) at Penang Botanical Garden. J Wildlife Parks 26: 39-46.

Covert HH, Byron C. 2002. Positional behavior of the red-shanked douc langur, Delacour's Langur and the white-cheeked crested gibbon at the Cuc Phuong Endangered Primate Rescue Center. Caring for primates: The program for the 19th Congress of the International Society of Primatology. Mammological Society of China, Beijing.

Delgado RA, van Schaik CP. 2000. The behavioral ecology and conservation of the orangutan (Pongo pygmaeus): a tale of two islands. Evol Anthropol 9: 201-218.

Descovich KA, Galdikas BM, Tribe A, Lisle A, Phillips CJ. 2011. Fostering appropriate behavior in rehabilitant orangutans (Pongo pygmaeus). Intl J Primatol 32: 616-633.

Doran DM. 1996. The comparative positional behavior of the African apes. In: McGrew WC, Nishida T (eds.). Great Ape Societies. Cambridge University Press, Cambridge.

Fleagle JG. 1976. Locomotion and posture of the Malayan siamang and implications for hominoid evolution. Folia Primatologica 26: 245269.

Fleagle JG. 1978. Locomotion, posture and habitat utilization in two sympatric Malayan leaf monkeys. In: Montogomery GE (eds.). Ecology of Arboreal Folivores. Smithsonian Press, Washington, DC.

Gebo-Daniel L. 1996. Climbing, brachiation, and terrestrial quadrupedalism: historical precursors of hominid bipedalism. Amer J Phys Anthropol 101: 55-92.

Hambali K, Md-Zain BM, Amir A. 2016. Daily movement, sleeping sites and canopy level use of habituated silvered-leaf monkeys (Trachypithecus cristatus) in Bukit Malawati, Kuala Selangor, Malaysia. J Sustain Sci Manag 11: 21-30. 
Hunt KD, Cant JG, Gebo DL, Rose MD, Walker SE, Youlatos D. 1996. Standardized descriptions of primate locomotor and postural modes. Primates 37: 363-387.

Isler K, Thorpe SKS. 2003. Gait parameters in vertical climbing of captive, rehabilitant and wild Sumatran orang-utans (Pongo pygmaeus abelii). J Exp Biol 206: 4081-4096.

Kamaluddin SN, Yaakop S, Idris WMR, Rovie-Ryan JJ, Md-Zain BM. 2018a. Subspecies identification of captive Orang Utan in Melaka based on D-loop mitochondria DNA. AIP Conference Proceedings 1940: 020055. DOI: $10.1063 / 1.5027970$.

Kamaluddin SN, Yaakop S, Idris WMR, Dharmalingam S, Rovie-Ryan JJ, Md-Zain BM. 2018b. Genetic Identification of Critically Endangered Orangutans in Captivity. J Sustain Sci Manag 13: 57-68.

Kamarul H, Ahmad I, Md-Zain BM, Syaizwan Z, Aainaa A. 2014 Ranging behavior of long-tailed macaques (Macaca fascicularis) at the entrance of Kuala Selangor Nature Park. Malaysia. Appl Biol 43: $129-142$.

Koari C. 2002. Suspensory behavior and its role in positional activities of Japanese macaques. Z Morph Anthropol 83: 325-335.

Kuncoro P. 2004. Aktivitas harian orangutan Kalimantan (Pongo pygmaeus Linneaus, 1760) rehabilitan di hutan lindung pegunungan Meratus, Kalimantan Timur. BSc Thesis. Universitas Udayana, Denpasar, Bali, Indonesia. [Indonesian]

Manduell K. 2008. Locomotor behaviour of wild orang-utans ( $P . p$. wurmbii) in disturbed peat swamp forest, Sabangau, Central Kalimantan, Indonesia. [Thesis]. Manchester Metropolitan University School, Manchester, UK.

Manduell KL, Morrogh-Bernard HC, Thorpe SK. 2011. Locomotor Behavior of wild orangutans (Pongo pygmaeus wurmbii) in disturbed peat swamp forest, Sabangau, Central Kalimantan, Indonesia. Amer J Phys Anthropol 145: 348-359.

Manduell KL, Harrison ME, Thorpe SK. 2012. Forest structure and support availability influence orangutan locomotion in Sumatra and Borneo. Amer J Primatol 74: 1128-1142.

Martin P, Bateson P. 1986. Measuring Behaviour. Cambridge University Press, Cambridge, UK

Md-Zain BM, Ruslin F, Idris WMR. 2014. Human-Macaque Conflict in the Main Campus, Universiti Kebangsaan Malaysia. Pertanika J Trop Agric Sci 37: 73-85.

Md-Zain BM, Ch`ng C-E. 2011. The Activity Patterns of a Group of Cantor' Dusky Leaf Monkeys (Trachypithecus obscurus halonifer). Intl J Zool Res 7: 59-67.

Md-Zain BM, Sha`ari NA, Mohd-Zaki M, Ruslin F, Idris NI, Kadderi MD, Idris WMR. 2010. A comprehensive population survey and daily activity budget on long tailed macaques of Universiti Kebangsaan Malaysia. J Biol Sci 10: 608-615.

Md-Zain BM, Masstor NH, Rosli MKA, Vun VF, Zakaria SS, Zainal ZZ, Rovie-Ryan, JJ, Lakim M, Ampeng, A, Shukor MN, Sabapathy D, Mahani MC. 2013. Phylogenetic relationships of the Bornean orang utan compared to other Malaysian primates using cytochrome $b$ DNA sequences. In: Latiff A, Mashhor M (eds.). Ex situ conservation of orang utan. Bukit Merah Orang Utan Island Foundation, Perak, Malaysia.

Michilsens F, Vereecke EE, D'Aout K. 2010. Muscle moment arms and function of the siamang forelimb during brachiation. J Anat 217: 521 535 .

Morrogh-Bernard H, Husson S, McLardy C. 2002. Orang-utan data collection standardisation. LSBLeakey Foundation Orang-utan Culture Workshop. San Anselmo, California.

Morrogh-Bernard H, Husson S, Page SE, Rieley JO. 2003. Population status of the Bornean orangutan (Pongo pygmaeus) in the Sebangau peat swamp forest, Central Kalimantan, Indonesia. Biol Conserv 110: $141-152$

Myatt JP. 2011. Applying An Ecomorphological Framework To The Study Of Orangutan Positional Behaviour and the Morphological Variation within Non-Human Apes. [Dissertation]. University of Birmingham, UK.
Myatt JP, Crompton RH, Thorpe SKS. 2011. Hindlimb muscle architecture in non-human great apes and a comparison of methods for analysing inter-species variation. J Anat 219: 150-166.

Myatt JP, Thorpe SK. 2011. Postural strategies employed by orangutans (Pongo abelii) during feeding in the terminal branch niche. Amer $\mathbf{J}$ Phys Anthropol 146: 73-82.

Nater A, Mattle-Greminger MP, Nurcahyo A, Nowak MG, de Manuel M, Desai T, Groves C, Pybus M, Sonay TB, Roos C, Lameira AR, Wich SA, Askew J, Davila-ross M, Fredriksson G, de Valles G, Casals F, Prado-Martinez J, Goossens B, Verschoor EJ, Warren KS, Singleton I, Marques DA, Pamungkas J, Perwitasari-Farajallah D, Rianti P, Tuuga A, Gut IG, Gut M, Orozcoter Wengel P, Van Schaik CP, Bertranpetit J, Anisimova M, Scally A, Marques-Bonet T, Meijaard E, Krützen M. 2017. Morphometric, behavioral, and genomic evidence for a new orangutan species. Curr Biol 27: 3487-3498.

Philips A. 2011. Locomotor Development and Gap Crossing Behaviour in Bornean Orangutans (Pongo pygmaeus). [Dissertation]. University of Birmingham, UK.

Putt S. 2009. Captive orangutan locomotion and its relation to the origin of human bipedalism. Nature 39: 23-37.

Remis MJ. 1995. The effects of body size and social context on the arboreal activities of western lowland gorillas in the Central African Republic. Am J Phys Anthropol 97: 413-433.

Richard A. 1985. Primates in Nature. W. H. Freeman, New York

Roos C, Boonratana R, Supriatna J, Fellowes JR, Groves CP, Nash SD, Rylands AB, Mittermeier RA. 2014. An updated taxonomy and conservation status review of Asian primates. Asian Primates J 4: 238

Rose MD. 1977. Positional behavior of olive baboons (Papio anubis) and its relationship to maintenance and social activities. Primates 18: 59116.

Ruslin F, Azmi MA, Matsuda I, Amir R, Md-Zain BM. 2017. Monkey school: Training phases for coconut-picking macaques (Macaca nemestrina). Malayan Nat J 69: 301-306

Ruslin F, Matsuda I, Md-Zain BM. 2019. The feeding ecology and dietary overlap in two sympatric primate species, the long-tailed macaque (Macaca fascicularis) and dusky langur (Trachypithecus obscurus obscurus), in Malaysia. Primates 60: 41-50.

Sugardjito J, van Hooff JA. 1986. Age-sex class differences in the positional behaviour of the Sumatran orang-utan (Pongo pygmaeus abelii) in the Gunung Leuser National Park, Indonesia. Folia Primatol Basel 47: 14-25.

Thorpe SKS, Crompton RH. 2005. Locomotor ecology of wild orangutans (Pongo pygmaeus abelii) in the Gunung Leuser ecosystem, Sumatra, Indonesia: a multivariate analysis using log-linear modelling. Am J Phys Anthropol 127: 58-78.

Thorpe SK, Crompton RH. 2006. Orangutan positional behavior and the nature of arboreal locomotion in Hominoidea. Amer J Phys Anthropol 131: 384-401.

Thorpe SKS, Crompton RH, Alexander RM. 2007. Orangutans use compliant branches to lower the energetic cost of locomotion. Biol Lett 3: 253-256.

Warren KS, Verschoor EJ, Langenhuijzen S, Heriyanto Swan RA, Vigilant L, Heeney JL. 2001. Speciation and Intrasubspecific Variation of Bornean Orangutans, Pongo pygmaeus pygmaeus. Mol Biol Evol 18: 472-480.

Workman C, Covert HH. 2005. Learning the ropes: The ontogeny of locomotion in red-shanked douc (Pygathrix nemaeus), Delacour's (Trachypithecus delacouri), and Hatinh langurs (Trachypithecus hatinhensis) I. positional behavior. Amer J Phys Anthropol 128: 371380.

Workman C, Schmitt D. 2012. Positional behavior of Delacour's langurs (Trachypithecus delacouri) in northern Vietnam. Intl J Primatol 33: 19-37.

Zhang YW, Ryder OA, Zhang YP. 2001. Genetic Divergence of Orangutan Subspecies (Pongo pygmaeus). Mol Evol 52: 516-526. 